\title{
Pial Artery Supply as an Anatomic Risk Factor for Ischemic Stroke in the Treatment of Intracranial Dural Arteriovenous Fistulas
}

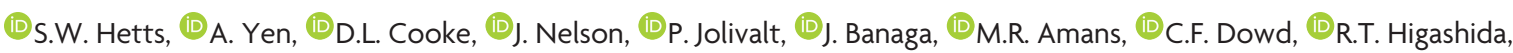 \\ (1) M.T. Lawton, ${ }^{-}$H. Kim, and DV.V. Halbach
}

\begin{abstract}
BACKGROUND AND PURPOSE: Although intracranial dural arteriovenous fistulas are principally supplied by dural branches of the external carotid, internal carotid, and vertebral arteries, they can also be fed by pial arteries that supply the brain. We sought to determine the frequency of neurologic deficits following treatment of intracranial dural arteriovenous fistulas with and without pial artery supply.
\end{abstract}

MATERIALS AND METHODS: One hundred twenty-two consecutive patients who underwent treatment for intracranial dural arteriovenous fistulas at our hospital from 2008 to 2015 were retrospectively reviewed. Patient data were examined for posttreatment neurologic deficits; patients with such deficits were evaluated for imaging evidence of cerebral infarction. Data were analyzed with multivariable logistic regression.

RESULTS: Of 122 treated patients, 29 (23.8\%) had dural arteriovenous fistulas with pial artery supply and $93(76.2 \%)$ had dural arteriovenous fistulas without pial arterial supply. Of patients with pial artery supply, 4 (13.8\%) had posttreatment neurologic deficits, compared with 2 patients $(2.2 \%)$ without pial artery supply $(P=.04)$. Imaging confirmed that 3 patients with pial artery supply $(10.3 \%)$ had cerebral infarcts, compared with only 1 patient without pial artery supply $(1.1 \%, P=.03)$. Increasing patient age was also positively associated with pial supply and treatment-related complications.

CONCLUSIONS: Patients with dural arteriovenous fistulas supplied by the pial arteries were more likely to experience posttreatment complications, including ischemic strokes, than patients with no pial artery supply. The approach to dural arteriovenous fistula treatment should be made on a case-by-case basis so that the risk of complications can be minimized.

ABBREVIATION: DAVF $=$ dural arteriovenous fistula

I ntracranial dural arteriovenous fistulas (DAVFs) are vascular malformations that connect meningeal arteries to dural venous sinuses or cortical veins. DAVFs account for $10 \%-15 \%$ of all intracranial arteriovenous shunting lesions. ${ }^{1-14}$ DAVFs are often thought to be acquired, sometimes in the setting of hypercoagulability. ${ }^{15}$ DAVF venous drainage determines the natural history risk of spontaneous intracranial hemorrhage. Thus, venous drainage is incorporated into the most commonly used grading systems of

Received February 28, 2017; accepted after revision August 3.

From the Department of Radiology and Biomedical Imaging (S.W.H., D.L.C., P.J., M.R.A., C.F.D., R.T.H., V.V.H.), School of Medicine (A.Y., J.B.), Departments of Anesthesia and Perioperative Care (J.N., P.J., C.F.D., R.T.H., H.K., V.V.H.), Neurological Surgery (C.F.D., R.T.H., M.T.L., V.V.H.), and Neurology (C.F.D., R.T.H., V.V.H.), University of California, San Francisco, San Francisco, California.

Paper previously presented, in part, at: Annual Meeting of the American Society of Neuroradiology, May 21-26, 2016; Washington, DC.

Please address correspondence to Steven W. Hetts, MD, 505 Parnassus Ave, L-352, San Francisco, CA 94143; e-mail: steven.hetts@ucsf.edu

三 Indicates article with supplemental on-line tables.

http://dx.doi.org/10.3174/ajnr.A5396
DAVF natural history risk: the Borden-Shucart and Cognard grading scales. ${ }^{2,3}$ Drainage to cortical veins is the highest risk category because pressurization of these thin-walled venous structures frequently leads to rupture. Although venous angioarchitecture is a key determinant of natural history risk, the risk of endovascular and/or surgical treatment of DAVFs in the modern era related to underlying lesion angioarchitecture is not well-known.

Although DAVFs are most commonly fed by dural branches of the internal carotid, external carotid, and vertebral arteries, they can also have pial artery supply. Pial arteries lie on the surface of the brain. They then branch into penetrating arteries and parenchymal arterioles that lie within and supply the brain parenchyma. The mechanism of pial feeder formation is not well-understood but is believed to be like that of dural feeders, with increased vascular endothelial growth factor secretion from the venous sinus and abnormal angiogenesis. ${ }^{16-24}$ Embolization of pial AVFs has been suggested to lead to the development of subsequent DAVFs in up to $25 \%$ of cases. ${ }^{25,26}$ The inflammatory reaction within the DAVF vessel wall after embolization may also lead to angiogenesis. ${ }^{27}$ 
Transarterial embolization of DAVFs with pial artery supply with agents that can migrate retrograde (ie, from the dural arteries to the pial arteries) could thus block blood supply to the associated brain parenchyma and cause ischemia. Surgical or endovascular point occlusion of DAVFs with pial artery supply at the fistula site might also result in retrograde thrombosis of feeding pial arteries due to decreased flow. We hypothesized that patients with DAVFs with pial artery supply have a higher risk of postoperative stroke than those who do not have pial supply.

\section{MATERIALS AND METHODS \\ Patient Population}

All patients undergoing neurointerventional procedures at the University of California, San Francisco hospitals are prospectively enrolled in an institutional review board-approved research data base. Patients in this study were treated at the University of California, San Francisco Medical Center or San Francisco General Hospital between 2008 and 2015. We compiled a cohort of 122 consecutive patients with intracranial DAVFs.

\section{Data Collection}

Retrospective analysis was conducted on 122 patients with DAVFs examined with digital subtraction angiography and treated with embolization and/or an operation at the University of California, San Francisco. Clinical information was extracted from electronic medical records and radiologic imaging reports. Pretreatment presentations, neurointerventional treatments, surgical treatments, and posttreatment outcomes were abstracted from the electronic medical records. Of note, all patients in our series were anticoagulated with intravenous heparin during our embolization procedures. All patients' initial and posttreatment DSA examinations were interpreted by an experienced interventional neuroradiologist and scored according to a structured angiographic case report form originally developed for brain AVMs by Atkinson et $\mathrm{al}^{7}$ and subsequently modified for intracranial DAVFs, including the Borden-Shucart and Cognard venous drainage scales. ${ }^{1-3,6}$ We have used this form in our prior studies of intracranial dural and pial arteriovenous fistulas ${ }^{8,26}$ and have chosen to use it again for consistency and comparability among studies. Radiologic studies (including MR imaging and CT) at each phase in the patients' treatments were assessed for imaging complications and correlation with clinical complications. Neurologic outcomes were individually tabulated and scored with the modified Rankin Scale of disability.

Patient data were examined for postembolization and postsurgical neurologic complications that resulted in strokelike symptoms, including cranial nerve palsies, altered mental status, focal weakness, decreased sensation, and speech or hearing difficulties. From this subset of patients with strokelike symptoms, imaging data were further examined for evidence of cerebral infarction. For analysis, strokes were considered a subset of neurologic deficits, which were, in turn, considered a subset of major complications.

\section{Statistical Analysis}

Patient characteristics, DAVF classifications, treatment modalities, and treatment-related outcomes were summarized for all pa- tients, patients with DAVF with pial supply, and patients with DAVF without pial supply. We tested whether patient characteristics were associated with pial supply using a 2-sample $t$ test for continuous variables. The Fisher exact test was used for nominal categoric variables; and logistic regression, for ordinal categoric variables. We treated the Borden-Shucart (grades I, II, and III) and Cognard (grades I, IIa, IIb, IIa + b, III, IV, V) venous drainage natural history scales as ordinal variables, because they increase numerically as the angioarchitectural complexity of the fistula increases; Cognard grades IIa, IIb, and IIa $+\mathrm{b}$ were grouped together during analysis. The modified Rankin Scale was also analyzed as an ordinal variable. We performed multivariable logistic regression analysis with any major complication as the outcome and with pial supply, age, and an operation as predictors. Given the small number of stroke and neurologic deficit events, they were not analyzed as separate outcomes in multivariable analysis. We considered $P$ values $\leq .05$ statistically significant. Data analysis was conducted with STATA 13.1 (StataCorp, College Station, Texas).

\section{RESULTS}

\section{Patient Population}

Summary statistics are presented in On-line Table 1. Of 122 patients, 29 (24\%) had DAVFs with pial supply. The average age at treatment of the study population was 59 years, and about half were women. Patients with pial-supply DAVFs were slightly older (63 versus 58 years of age, $P=.049$ ). There was an association of Borden-Shucart and Cognard grades with the presence of pial artery supply: the higher the Borden-Shucart score, the more likely it was that the DAVF had a pial supply $(\mathrm{OR}=1.72, P=$ .035). For the Cognard grading system, higher grade DAVFs were more likely to have pial supply, but this finding was not significant $(\mathrm{OR}=1.31, P=.135)$. Patients with DAVFs with pial supply also tended to have poorer pretreatment mRS assessment outcomes, but not significantly so $(\mathrm{OR}=1.22, P=.131)$.

\section{Modes and Outcomes of Treatment}

Most patients (70\%) were treated with embolization exclusively. Pial supply was not associated with the type of treatment (embolization versus an operation versus a combination of embolization and an operation) received $(P=.267)$. When we compared an operation versus no operation (irrespective of embolization), patients with DAVFs with pial supply were more likely to have undergone an operation (41\%, 12/29 patients) than those without pial supply (26\%, 24/93 patients), but this difference was not statistically significant $(P=.160)$. However, DAVFs with pial supply were significantly more likely to receive transarterial embolization than those without a pial supply ( $92 \%$ [24/26 patients] versus $59 \%$ [51/86 patients], $P=.002$ ). DAVFs with pial supply were less likely to be fully cured on the basis of posttreatment angiography (55\% [16/29 patients] versus 76\% [71/93 patients], $P=.035)$.

\section{Major Complications, Neurologic Deficits, and Strokes}

As outlined above, strokes were considered a subset of neurologic deficits, which were, in turn, considered a subset of major complications. Four treatment-related strokes, 6 neurologic deficits, and 15 major complications were observed. Specific characteris- 


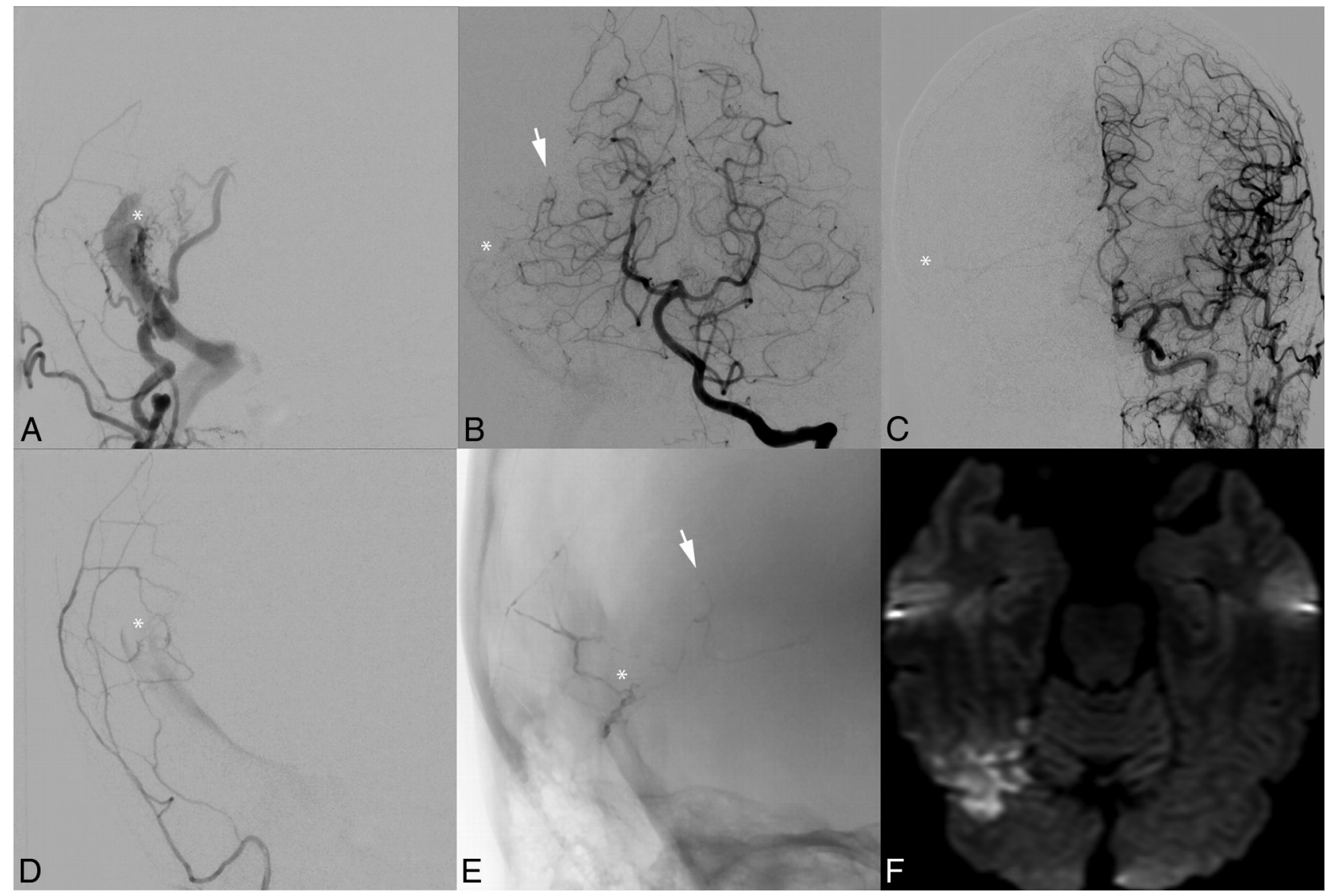

FIG 1. Postembolization infarction due to Onyx migration into a pial artery. A middle-aged woman with severe pulsatile tinnitus underwent endovascular therapy for a right transverse-sigmoid sinus junction Borden-Shucart grade I DAVF supplied principally by the middle meningeal and occipital arteries $(A)$ and secondarily by the ipsilateral middle temporal artery $(B)$ and tentorial branches from the contralateral middle meningeal artery $(C)$. The fistula site is designated by a white asterisk. The fusiform gyrus branch of the middle temporal artery is indicated by a white arrow. Superselective injection of the right middle meningeal artery demonstrates the fistula site before embolization ( $D$ ). Midembolization $x$-ray $(E)$ demonstrates Onyx in the middle meningeal artery, fistula site, and refluxed into the pial fusiform gyrus branch of the middle temporal artery. The extent of reflux had not been evident on real-time intraprocedural blank roadmap imaging. DWI later the same day $(F)$ demonstrates a fusiform gyrus infarction.

tics of patients who had symptomatic ischemic strokes are detailed in On-line Tables 2 and 3, and details regarding all patients with major complications are included in On-line Table 4. DAVFs with pial supply were associated with more strokes (10\% versus $1 \%, P=.041$ ), neurologic deficits ( $14 \%$ versus $2 \%, P=.028$ ), and major complications ( $28 \%$ versus $8 \%, P=.008$ ). Pial supply remained associated with major complications in multivariable analysis $(\mathrm{OR}=3.66, P=.030)$, when adjusting for age $(\mathrm{OR}=$ 1.45 per decade increase, $P=.166)$ and an operation $(\mathrm{OR}=3.36$, $P=.044)$.

\section{DISCUSSION}

Intracranial DAVFs are rare, and a small subset are supplied by not only dural arteries but also pial arteries. Because pial arteries also supply the brain parenchyma, blockage of blood flow through pial arteries can potentially cause an ischemic stroke. Indeed, we found that DAVFs supplied by pial arteries are associated with a higher risk of developing neurologic deficits, stroke, and major complications after treatment. Furthermore, patients with pial supply tended to be slightly older than patients without pial supply, and increasing age was significantly associated with posttreatment complications. Pial supply to the DAVFs appears to be a marker for greater complexity and the potential for com- plications, possibly due to several mechanisms, including retrograde reflux of liquid embolics to pial vessels (Fig 1), periprocedural hypercoagulability (Fig 2), retrograde thrombosis of pial arteries (Fig 3), and venous infarction with hemorrhage (Fig 4). To date, DAVF grading scales (eg, Borden-Shucart and Cognard) have focused on natural history risk for venous rupture, not on the risk of treatment. Identifying consistent risk factors for adverse outcomes following treatment is the first step in establishing a grading scale for treatment risk of DAVFs in the modern endovascular and surgical era, akin to what has been done with great success for brain AVMs with the Spetzler-Martin and LawtonYoung supplementary grading scales for surgical treatment risk. ${ }^{9,16}$

The criterion standard for identifying and treating DAVFs is conventional angiography, followed by embolization of the fistula when possible and an operation when embolization is not possible or is incomplete, particularly with lesions with a high natural history risk for rupture. In the past, DAVFs were treated with a combination of multiple embolic agents, including detachable coils, ethanol, $n$-BCA glue, silk sutures, and polyvinyl alcohol particles. ${ }^{7,10,11,14}$ The recent emergence of ethylene-vinyl alcohol copolymer (Onyx; Covidien, Irvine, California) has allowed the use 
of a single transarterial embolic agent in many cases. ${ }^{13}$ A large series of DAVF treatments from the Barrow Neurological Institute ${ }^{5}$ recently demonstrated a higher initial occlusion rate via embolization from a single arterial pedicle in the Onyx era compared with the pre-Onyx era, with a similar permanent neurologic complication rate ( $2 \%$ pre-Onyx versus $3 \%$ post-Onyx). If initial embolization is unsuccessful or incomplete, subsequent emboliza-

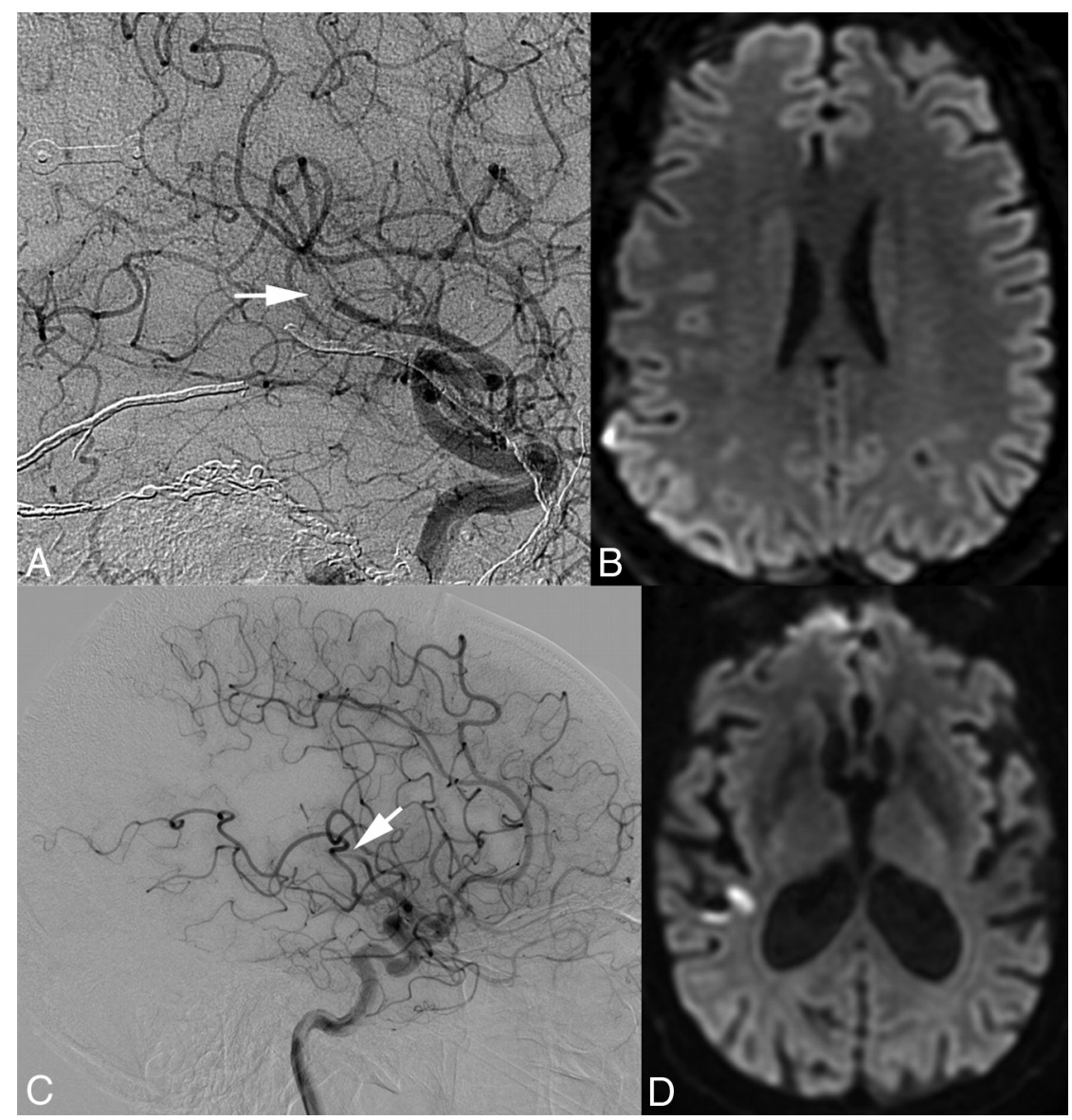

FIG 2. Arterial emboli following endovascular and surgical treatments of DAVFs in 2 patients. Two middle-aged male patients undergoing posttreatment angiography were identified as having middle cerebral artery emboli ( $A$ and $C$, white arrows). Both patients were heparinized, and the second patient underwent superselective intra-arterial tPA treatment with minimal clot lysis. Postangiographic DWls $(B$ and $D)$ demonstrate small cortical infarctions in territories associated with the MCA emboli. Although the first patient's MCA thrombus ( $A$ and $B)$ is adjacent to the original DAVF, the second patient's is not ( $C$ and $D)$. tions or craniotomy with surgical clipping or resection can be performed. Although rare, some DAVFs have a very aggressive clinical course and can progress or recur. ${ }^{6}$

Onyx is a liquid embolic agent that has been used more frequently for embolization of DAVFs and AVMs in recent years. Its emergence has allowed the use of a single agent and has caused the use of ethanol, detachable coils, and $n$-BCA glue to decline. Because Onyx is a liquid agent, its path throughout the vasculature cannot always be perfectly controlled, particularly if the Onyx is poorly seen against the bones of the skull base on real-time road-mapping (Fig 1). We believe that the mechanism by which at least some of the strokes reported above occur involves retrograde reflux of Onyx from pial artery feeders to the DAVF into segments of pial arteries that do not supply the DAVF but instead supply the brain parenchyma. This subsequently blocks blood flow to portions of the brain parenchyma and causes infarction. A potential technique to prevent dural-to-pial reflux of Onyx is prophylactically sealing the distal pial arteries supplying a DAVF, for example, by navigating a flow catheter as distal as possible and using $n$-BCA glue to seal off the pial connections into the DAVF. This technique has been advocated to lower hemorrhage risk in a DAVF operation. ${ }^{17}$ Such an approach, however, poses a risk for retrograde thrombosis of the pial feeding artery. Thus, if the pial feeding artery supplies an eloquent region of the brain, this technique may pose a risk of stroke in and of itself. Given the long track record of safe transvenous coil embolization of intracranial DAVFs, our practice is to use this technique when possible, particularly if the pial artery supply to a fistula is identified.

Reflux of Onyx does not explain infarctions that occurred after the operation. Instead, precise surgical ligation of

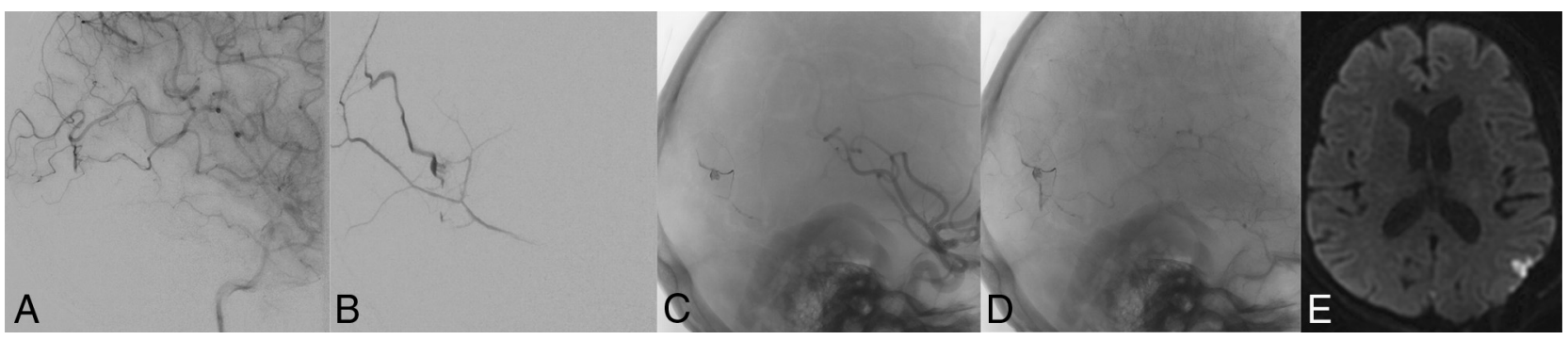

FIG 3. Postsurgical seizure and small cortical infarction after surgical ligation of a residual DAVF. A middle-aged woman status 1 year post temporal lobe hemorrhage underwent endovascular therapy for a Borden-Shucart grade III DAVF supplied principally by the left middle meningeal artery $(B)$ and secondarily by pial branches of the left MCA $(A)$, with drainage directly to a cortical vein. Onyx embolization eliminated the middle meningeal artery dural supply $(C)$, but late-phase angiographic images demonstrated persistent MCA pial supply $(D)$. Three days following a craniotomy for successful ligation of the residual DAVF, the patient had a seizure. MR imaging at that time demonstrates a small cortical infarction $(E)$. 


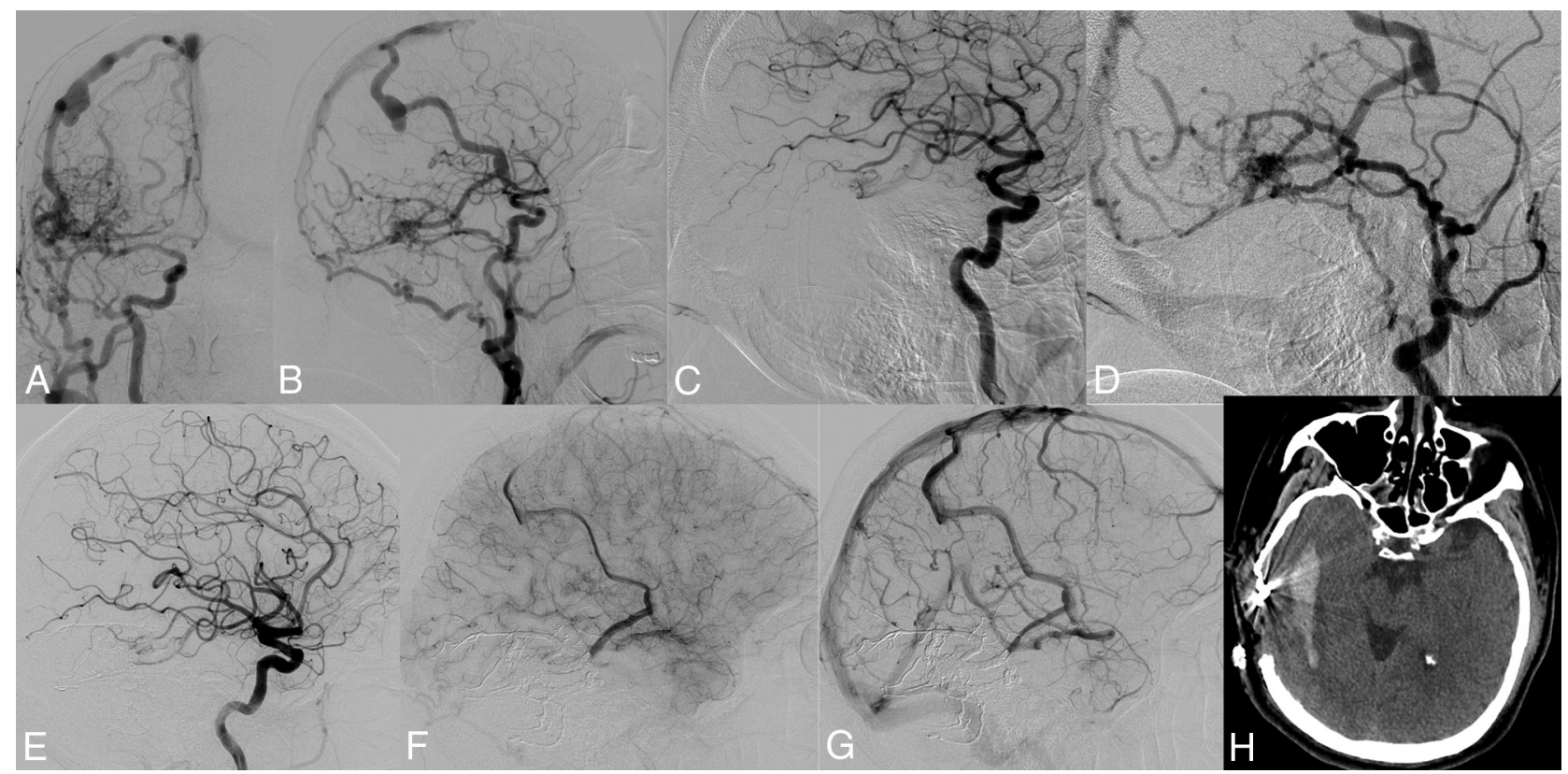

FIG 4. Postoperative parenchymal hemorrhage and possible venous infarction following surgical ligation of a residual DAVF. A middle-aged man had intermittent speech arrest and multiple headaches for several years. Anteroposterior $(A)$ and lateral $(B)$ angiograms demonstrate a varianttype right transverse-sigmoid sinus junction Borden-Shucart grade III DAVF supplied by dural branches of the external carotid artery and pial branches of the MCA $(C)$ with retrograde drainage to the vein of Labbé $(D)$, that anastomotically drains to the vein of Trolard. Following Onyx embolization of the dural external carotid artery branches, only the pial MCA supply to the fistula continued to drain to the cortical vein as demonstrated on early $(E)$, mid $(F)$, and late $(G)$ images from a lateral ICA angiogram. During surgical ligation of the residual DAVF, extensive intraoperative bleeding was noted. A CT performed immediately postoperatively $(H)$ demonstrates right temporal intraparenchymal hemorrhage. The patient did not have a new neurologic deficit postoperatively.

a fistula site with significant pial supply will interrupt flow in the distal pial artery just proximal to the fistula site. This flow arrest in the pial feeder to the DAVF may result in retrograde thrombosis of the pial artery feeder to the next most proximal arterial branchpoint. In our experience, this has led to a few small cortical infarctions. Underlying patient hypercoagulability (a risk factor for DAVF formation in the first place) might also play a role in postoperative retrograde feeding artery thrombosis (Fig 3) as well as parent artery emboli (Fig 2); thus, pial supply may also be an indirect marker for a higher risk of thromboembolic complications separate from those seen intraprocedurally.

Recently, DAVFs with pial artery supply were shown to result in intraoperative hemorrhage in $33 \%$ of patients ${ }^{17}$ — significantly more than in patients with DAVFs without pial artery supply. Although symptomatic intraoperative hemorrhage was not seen in any of our cases (though an asymptomatic hemorrhage is shown in Fig 4), it helps support our assertion that DAVFs with pial artery supply carry a higher operative risk, and treatment should be approached with appropriate caution.

There were several limitations to this study. It was a retrospective review conducted at a single institution during an 8-year time span. Although the patient population consisted of 122 subjects, the low rate of clinical complications may affect the reliability of inferring statistical significance. Certain comparisons that are not statistically significant, given the small sample size, may, in fact, prove to be clinically significant. If a patient had a radiographic abnormality (eg, focal reduced diffusion on an MR imaging after DAVF) but not a neurologic deficit on clinical examination, the patient would not have been captured in our initial screen for complications, potentially reducing the number of complications identified. However, given that clinical complications are the focus of our analysis, we deemed this approach to be appropriate. Because our institution receives many outside referrals, our patient population may consist of higher risk cases, more complex lesions, and lesions that require staged multimodal treatments tailored to the natural history risk of each unique fistula. In some cases, we choose to stop short of lesion cure to avoid potential complications. Finally, follow-up was highly variable, and subsequent delayed complications may not have been available to us.

\section{CONCLUSIONS}

A small subset of intracranial DAVFs is supplied not only by dural arteries but also by pial arteries, raising the potential for increased risk of stroke or major complications during embolization or an operation. Special attention must be paid to the treatment of DAVFs with pial artery supply to minimize the potential for complications. Preprocedural counseling of patients and their families about the elevated treatment risk of DAVFs found to have a pial supply (often evident only on DSA) is prudent and may influence treatment decisions.

Disclosures: Steven W. Hetts—UNRELATED: Grants/Grants Pending: Siemens, Stryker, MicroVention Terumo, Comments: research contracts*; Royalties: Penumbra, Comments: royalty agreement for a device. ${ }^{*}$ Matthew R. Amans-UNRELATED: Consultancy: Medtronic. Christopher F. Dowd — UNRELATED: Other: MicroVention, Comments: I serve as Chief Adjudicator for the FRED Trial*. *Money paid to the institution.

\section{REFERENCES}

1. Newton TH, Cronqvist S. Involvement of the dural arteries in intracranial arteriovenous malformations. Radiology 1969;93:1071-78 CrossRef Medline 
2. Cordonnier C, Al-Shahi Salman R, Bhattacharya JJ, et al; IVMS Collaborators. Differences between intracranial vascular malformation types in the characteristics of their presenting haemorrhages: prospective, population-based study. J Neurol Neurosurg Psychiatry 2008;79:47-51 CrossRef Medline

3. Lasjaunias P, Manelfe C, Chiu M. Angiographic architecture of intracranial vascular malformations and fistulas: pretherapeutic aspects. Neurosurg Rev 1986;9:253-63 CrossRef Medline

4. Singh V, Smith WS, Lawton MT, et al. Risk factors for hemorrhagic presentation in patients with dural arteriovenous fistulae. Neurosurgery 2008;62:628-35; discussion 628-35 CrossRef Medline

5. Borden JA, Wu JK, Shucart WA. A proposed classification for spinal and cranial dural arteriovenous fistulous malformations and implications for treatment. J Neurosurg 1995;82:166-79 CrossRef Medline

6. Cognard C, Gobin YP, Pierot L, et al. Cerebral dural arteriovenous fistulas: clinical and angiographic correlation with a revised classification of venous drainage. Neuroradiology 1995;194:671-80 CrossRef Medline

7. Atkinson RP, Awad IA, Batjer HH, et al; Joint Writing Group of the Technology Assessment Committee American Society of Interventional and Therapeutic Neuroradiology; Joint Section on Cerebrovascular Neurosurgery a Section of the American Association of Neurological Surgeons and Congress of Neurological Surgeons; Section of Stroke and the Section of Interventional Neurology of the American Academy of Neurology. Reporting terminology for brain arteriovenous malformation clinical and radiographic features for use in clinical trials. Stroke 2001;32:1430-42 CrossRef Medline

8. Hetts SW, Tsai T, Cooke DL, et al. Progressive versus nonprogressive intracranial dural arteriovenous fistulas: characteristics and outcomes. AJNR Am J Neuroradiol 2015;36:1912-19 CrossRef Medline

9. Lawton MT, Kim H, McCullouch CE, et al. A supplementary grading scale for selecting patients with brain arteriovenous malformations for surgery. Neurosurgery 2010;66:702-13; discussion 713 CrossRef Medline

10. Spetzler RF, Martin NA. A proposed grading system for arteriovenous malformations. J Neurosurg 1986;65:476-83 CrossRef Medline

11. Hu YC, Newman CB, Dashti SR, et al. Cranial dural arteriovenous fistula: transarterial Onyx embolization experience and technical nuances. J Neurointerv Surg 2011;3:5-13 CrossRef Medline

12. Loh Y, Duckwiler GR; Onyx Trial Investigators. A prospective, multicenter, randomized trial of the Onyx liquid embolic system and $\mathrm{N}$-butyl cyanoacrylate embolization of cerebral arteriovenous malformations: clinical article. J Neurosurg 2010;113:733-41 CrossRef Medline

13. McConnell K, Tjoumakaris S, Allen J, et al. Neuroendovascular man- agement of dural arteriovenous malformations. Neurosurg Clin N Am 2009;20:431-39 CrossRef Medline

14. Signorelli F, Gory B, Maduri R, et al. Intracranial dural arteriovenous fistulas: a review of current management based on emerging knowledge. J Neurosurg Sci 2017;61:193-206 CrossRef Medline

15. Saraf R, Shrivastava M, Kumar N, et al. Embolization of cranial dural arteriovenous fistulae with ONYX: indications, techniques, and outcomes. Indian J Radiol Imaging 2010;20:26-33 CrossRef Medline

16. Gross BA, Albuquerque FC, Moon K, et al. Evolution of treatment and a detailed analysis of occlusion, recurrence, and clinical outcomes in an endovascular library of $\mathbf{2 6 0}$ dural arteriovenous fistulas. J Neurosurg 2017;126:1884-93 CrossRef Medline

17. Wu Q, Zhang XS, Wang HD, et al. Onyx embolization for tentorial dural arteriovenous fistula with pial arterial supply: case series and analysis of complications. World Neurosurg 2016;92:58-64 CrossRef Medline

18. Uranishi R, Nakase H, Sakaki T. Expression of angiogenic growth factors in dural arteriovenous fistula. J Neurosurg 1999;91:781-86 CrossRef Medline

19. Gupta A, Periakaruppan A. Intracranial dural arteriovenous fistulas: a review. Indian J Radiol Imaging 2009;19:43-48 CrossRef Medline

20. Shin Y, Nakase H, Nakamura M, et al. Expression of angiogenic growth factor in the rat DAVF model. Neurol Res 2007;29:727-33 CrossRef Medline

21. Tirakotai W, Bertalanffy H, Liu-Guan B, et al. Immunohistochemical study in dural arteriovenous fistulas and possible role of local hypoxia for the de novo formation of dural arteriovenous fistulas. Clin Neurol Neurosurg 2005;107:455-60 CrossRef Medline

22. Wang SS, Li CH, Zhang XJ, et al. Investigation of the mechanism of dural arteriovenous fistula formation induced by high intracranial venous pressure in a rabbit model. BMC Neurosci 2014;15:101 CrossRef Medline

23. Li Q, Zhang $\mathrm{Q}$, Huang $\mathrm{QH}$, et al. A pivotal role of the vascular endothelial growth factor signaling pathway in the formation of venous hypertension-induced dural arteriovenous fistulas. Mol Med Rep 2014;9:1551-58 CrossRef Medline

24. Lee JY, Son YJ, Kim KE. Intracranial pial arteriovenous fistulas. J Korean Neurosurg Soc 2008;44:101-04 CrossRef Medline

25. Paramasivam S, Toma N, Niimi Y, et al. De novo development of dural arteriovenous fistula after endovascular embolization of pial arteriovenous fistula. J Neurointerv Surg 2013;5:321-26 CrossRef Medline

26. Hetts SW, Keenan K, Fullterton HJ, et al. Pediatric intracranial nongalenic pial arteriovenous fistulas: clinical features, angioarchitecture, and outcomes. AJNR Am J Neuroradiol 2012;33:1710-19 CrossRef Medline

27. Buell TJ, Ding D, Starke RM, et al. Embolization-induced angiogenesis in cerebral arteriovenous malformations. J Clin Neurosci 2014; 21:1866-71 CrossRef Medline 